\title{
Protótipo de uma Ferramenta de Software para Apoio no Tratamento de Crianças com Autismo
}

\author{
Ezequiel B. Farias, Mônica X. C. Cunha \\ Instituto Federal de Educação, Ciência e Tecnologia de Alagoas (IFAL) - Campus \\ Maceió - Maceió - AL - Brasil \\ ezequiel_maceio@yahoo.com.br, mxcc@hotmail.com
}

\begin{abstract}
It is well known that the use of technology has brought numerous benefits in treating diseases, autism is not out of this reality. Because it is a syndrome characterized by failures in specific areas and on different levels, it ends up requiring adequacy of mechanisms used for the treatment of individuals who have, in this universe activities including literacy, critical step in treatment. The project itself aims to develop the initial modules of a tool that assists autistic children in literacy, seeking to boost the use of TEACCH methodology currently applied manually, and internalized by children already receiving some type of monitoring.
\end{abstract}

Resumo: É notório que o uso da tecnologia vem trazendo inúmeros beneficios no tratamento de doenças, o autismo não está fora desta realidade. Por ser uma síndrome caracterizada por falhas em áreas especificas e em níveis diversos, a mesma acaba exigindo adequação dos mecanismos utilizados para o tratamento de individuos que a apresentam, incluindo neste universo as atividades alfabetizadoras, etapa fundamental no tratamento. $O$ objetivo deste artigo é apresentar o protótipo de um software que auxilie na alfabetização de crianças autistas, procurando dinamizar o uso da metodologia TEACCH, atualmente aplicada de forma manual, e já internalizada por crianças que recebem algum tipo de acompanhamento.

\section{Introdução}

Autismo não é uma doença única, mas sim um distúrbio de desenvolvimento complexo, definido de um ponto de vista comportamental, com etiologias múltiplas e graus variados de severidade (RUTTER; SCHOPLER, 1992). As manifestações comportamentais que definem o autismo incluem déficits qualitativos na interação social e na comunicação, padrões de comportamento repetitivos e estereotipados e um repertório restrito de interesses e atividades (RAPIN, 1991). O termo autismo é oriundo da palavra grega autos que significa próprio ou de si mesmo sendo utilizado pela primeira vez por Bleuler em 1911, para designar a perda do contato com a realidade, que acarretava uma grande dificuldade ou impossibilidade de comunicação.

Segundo Camargos (2005), o autismo originalmente referia-se a um transtorno básico da esquizofrenia, porém com o passar dos anos esta concepção foi abandonada e 
passou-se a creditar causas neurobiológicas ao autismo. Ainda não existem exames clínicos que possam contribuir significativamente para o diagnóstico do autismo, sendo o mesmo obtido através da observação comportamental (COELHO, 2006). Entretanto existem as escalas de diagnósticos DSM-IV-TR e o CID-10, que se baseiam em três critérios essenciais: a) déficits qualitativos na interação social; b) atraso e déficit de linguagem e comunicação; c) comportamentos, atividades ou interesses restritos, repetitivos e estereotipados (SANTOS, 2009).

Dentro desta tríade a criança autista pode apresentar comportamentos obsessivos e ritualísticos como o apego à rotina rígida e obsessão por objetos enquadrando-se estes na dificuldade de imaginação, que se estende às várias áreas do pensamento e prejudica claramente qualquer tentativa de transmissão de conhecimento. Além disso, a rigidez e inflexibilidade do pensamento revela a falta de aceitação a mudanças e dificuldades em processos criativos (MELO, 2001, p.15). Todas estas características do espectro tornam a aprendizagem de crianças autistas uma tarefa difícil, mas não impossível de ser realizada. Atualmente o método que vem obtendo os melhores resultados neste campo é o TEACCH.

Criado em 1966, na divisão de Psiquiatria da Escola de Medicina da Universidade da Carolina do Norte (EUA), por Eric Schopller e colaboradores, o TEACCH ou Tratamento e Educação para Autistas e Crianças com Déficits relacionados à Comunicação é um programa que envolve as esferas de atendimento educacional e clínico, em uma prática com abordagem psicoeducativa, tornando-o por definição, um programa transdisciplinar (KWEE, 2006). Este programa tem como base a teoria comportamental e a psicolinguística, sendo as mesmas evidenciadas na valorização das descrições das condutas, utilização de programas passo a passo, uso de reforçadores e utilização de recursos visuais, proporcionando assim interação entre pensamento e linguagem, resultando na ampliação das capacidades de compreensão (LEON, 2002).

Para que toda esta prática seja possível é necessário entender a condição neurobiológica da síndrome em cada indivíduo, a partir daí o programa procura promover a adaptação, melhorando todas as habilidades para o viver através das melhores técnicas educacionais disponíveis e planejar estruturas ambientais que possam compensar os possíveis déficits existentes na criança. Percebe-se aqui que os programas específicos de ensino e tratamento, são individualizados e baseados em uma compreensão personalizada de cada indivíduo (KWEE, 2006).

O TEACCH trabalha com a estruturação externa do ambiente, do tempo, das atividades e dos materiais, com intuito de minimizar os déficits que a criança autista apresenta e proporcionar a aquisição de comportamentos adequados ao convívio social. Neste ponto a alfabetização tem papel fundamental, uma vez que a aquisição da leitura e da escrita, ao tempo que se revela como uma forma de inclusão social possibilita a capacidade criadora e o posicionamento crítico do mundo no qual o individuo está inseridos (MORAIS, 2010).

Atualmente, as atividades adaptadas do TEACCH são elaboradas de forma manual o que dificulta o trabalho dos profissionais que as confeccionam, uma vez que precisam ser individualizadas acompanhando o nível de desenvolvimento de cada criança. Além disso, a própria metodologia exige que haja uma repetição na execução das atividades por parte da criança autista, devendo a mesma ocorrer até que as habilidades trabalhadas na atividade sejam adquiridas. Outros fatores que merecem 
destaque são a procura por elementos que se ajustem ao propósito da atividade colocada para a criança e a montagem de uma sequência de atividades a serem executadas que deverão obedecer, além do nível de desenvolvimento, a disponibilidade da criança para o tratamento. Todas estas particularidades inerentes ao TEACCH aumentam significativamente o esforço dos profissionais que participam do processo.

Os fatores mencionados anteriormente tornam este processo alfabetizatório bastante diversificado e, portanto, ideal para ser disponibilizado em um programa de computador. Sabendo-se que o computador é um aliado poderoso neste processo, uma vez que cria um ambiente de aprendizagem em que o lúdico, a solução de problemas, a atividade reflexiva e a capacidade de decisão são privilegiados e que proporciona uma aprendizagem ativa, controlada pela criança, já que permite à mesma representar ideias, comparar resultados, refletir sobre sua ação e tomar decisões, depurando o processo de aprendizagem. Além disso, por ser um agente facilitador o computador de uma maneira geral, atrai as atenções das crianças fazendo com que fiquem voltadas a ele e interessadas no seu trabalho (BERNARDI, 2010).

É neste cenário que o presente estudo se projeta, procurando apresentar os resultados parciais alcançados no processo de construção de um software voltado para a alfabetização de crianças autistas. O pioneirismo aqui não está no fato de se criar uma ferramenta alfabetizatória voltada para crianças autistas, uma vez que nossas pesquisas revelaram alguns instrumentos com este propósito, e sim produzir uma ferramenta totalmente alinhada aos benefícios advindos da metodologia TEACCH, método amplamente utilizado, internalizado e comprovadamente eficaz na abordagem com estas crianças. A utilização de uma ferramenta como a que propõe este trabalho, representaria ganhos significativos, tanto para o profissional que teria o seu trabalho otimizado, com um maior controle sobre o processo alfabetizatório, como para a criança que teria uma maior diversidade de atividades, interface apropriada à disposição, facilitando o seu processo de aprendizagem.

\section{Metodologia}

Inicialmente se fez necessário o entendimento da realidade autista. Para isso foi realizado um estudo bibliográfico que permitiu identificar particularidades do espectro que pudessem compor funcionalidades no software que se pretende construir. Durante o processo de levantamento bibliográfico algumas ferramentas voltadas para a abordagem com portadores de autismo foram identificadas, dentre elas o Aba Math, Mouse Trial, P.A.L.S. (Progressive Autism Learning System) etc. Porém, nenhuma delas reflete os propósitos da metodologia TEACCH, fator motivador para o estudo. Para um entendimento mais efetivo da problemática autista, uma pesquisa de campo foi realizada em uma instituição que atualmente presta atendimento multidisciplinar a crianças autista em Maceió, a Associação de Amigos do Autista de Alagoas (AMA-AL). Existem associações similares em todo território nacional. Ficou claro na revisão bibliográfica que há uma carência de softwares voltados para auxiliar no processo conduzido pelos profissionais, bem como no tratamento das crianças que atualmente recebem algum tipo de acompanhamento, seja à nível de instituição ou até mesmo em casa ou na escola.

A investigação realizada na AMA-AL permitiu observar a metodologia TEACCH sendo aplicada na prática, qual a intervenção realizada pelos profissionais durante o tratamento, como as atividades são elaboradas e apresentadas para as crianças, quais os 
compartimentos para armazenagem, como o ambiente é preparado para receber as crianças, quais os estímulos dados à criança no ato de execução das atividades, quais as técnicas utilizadas para evitar distrações da criança, etc. Dentro do universo das atividades, foram observados os materiais utilizados na confecção das atividades, como estes são manipulados pelas crianças, a disposição das cores nas tarefas, qual a hierarquia e ordem das atividades elaboradas, quais assuntos abordados em cada nível do TEACCH. Enfim, tudo que serve de base para a especificação dos requisitos e consequentemente elaboração de uma ferramenta eficaz e completa. Em etapas mais avançadas da investigação foi possível averiguar a complexidade envolvida em cada nível de tarefas, habilidades trabalhadas em cada nível, quais os indicativos observados pelos profissionais para definir a passagem de nível de uma criança, dificuldades enfrentadas pelas terapeutas e pedagogas na elaboração das atividades, sempre comparando com as recomendações do TEACCH.

Além da observação se fez necessário a realização de entrevistas com o corpo de profissionais atuantes na instituição visitada, com o intuito de validar todo material colhido até o momento com o estudo. Sendo assim, foram registrados os diversos depoimentos trazidos por aqueles que conduzem diariamente os tratamentos na referida instituição, onde foi possível identificar um padrão de opiniões. A maioria afirmou que a melhor forma de lidar com crianças autistas, é estabelecendo contato com elas, pois cada uma apresenta maneira particular de se comportar, manifestando os sintomas do espectro autístico em níveis e formas peculiares; porém, é necessário que este contato seja antecedido por um conhecimento teórico para melhor atendê-las. Os resultados obtidos com esta etapa revelaram que as visitas à instituição foram fundamentais para enriquecer o estudo, uma vez que o convívio com as crianças permitiu entender cada vez mais o mundo particular de cada uma delas.

A AMA-AL, espaço que propiciou o estudo, é uma associação sem fins lucrativos, formada por pais de crianças com autismo, que buscam evolução no quadro clinico de seus filhos. Criada em 2008, a AMA-AL atende atualmente 30 crianças na fixa etária de 02 a 12 anos, sendo todas distribuídas nos turnos manhã e tarde, com diagnóstico de transtorno invasivo do desenvolvimento e residentes em Maceió e adjacências. Os tratamentos são conduzidos por profissionais e estagiários da área de psicologia, fonoaudiologia, terapia ocupacional, pedagogia, música, educação física, artes e informática, que realizam um trabalho fundamental, visto que os atendimentos multidisciplinares propiciam às crianças uma vida mais autônoma e produtiva ${ }^{1}$.

Após a identificação dos requisitos, foi possível especificar os diagramas de caso de uso, CDU's, bem como elaborar os modelos de tela do software, que inclusive sofreram reajustes à medida que novas funcionalidades foram identificadas. A análise constante destes modelos permitiu ter um maior domínio sobre o funcionamento do sistema resultando na elaboração do banco de dados do software que, uma vez definido, possibilitou a realização de uma pesquisa e diagramação de elementos para o seu povoamento. Nesta etapa foram utilizadas ferramentas que auxiliaram todo o processo, como o Pencil para a elaboração dos modelos de tela e o Astah Comunnity para a diagramação e modelagem do banco de dados do sistema.

\footnotetext{
${ }^{1}$ Conforme informações apresentadas no site da AMA-AL, disponível em ww.autismoalagoas.org.br, acesso em 09 de janeiro de 2013.
} 
Toda modelagem e documentação gerada foi apresentada a duas profissionais de São Paulo, cujo trabalho é nacionalmente conhecido na área de autismo, sendo uma psicóloga e uma fonoaudióloga, com mestrado e doutorado, respectivamente, na área de educação especial, que acrescentaram sugestões de melhoria das características inicialmente pensadas para o sistema, bem como a inserção de novas funcionalidades agregando inda mais valor ao estudo.

Os resultados preliminares obtidos nessa etapa, que serão descritos na próxima seção, servirão de apoio para a codificação da ferramenta, fornecendo reais dimensões de cada funcionalidade, das ligações existentes entre as classes assim como o escopo de cada uma delas. Durante o processo de criação dos protótipos iniciais de telas foi realizada uma pesquisa em sites da internet na procura por imagens, desenhos que retratassem visualmente, o mais fidedignamente possível, a estrutura física do ambiente proposto pela metodologia TEACCH.

\section{Resultados}

O domínio sobre os requisitos do sistema permitiram iniciar o processo de diagramação e design dos modelos de tela, tentando aqui representar todas as características pensadas para o sistema. Esta etapa sofreu constantes melhorias e incrementos, tentando aproximar ao máximo o virtual do real. A pretensão é construir um modelo totalmente alinhado aos princípios da metodologia TEACCH que possa otimizar o trabalho realizado pelos profissionais e consequentemente proporcionar as crianças uma ferramenta prazerosa e eficaz em seus tratamentos. Para que isso seja possível é preciso entender o papel exercido por cada integrante em nível de sistema. O diagrama de caso de uso apresentado na Figura 1 apresenta a dimensão exata destes papéis.

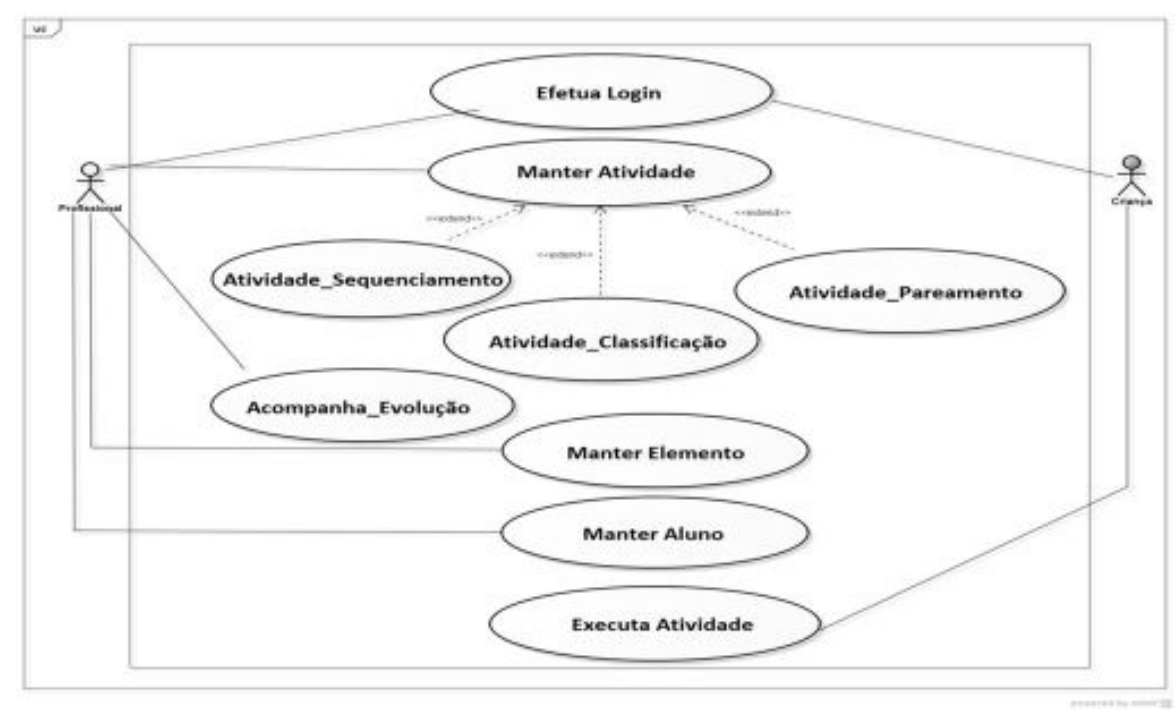

Figura 1 - Diagrama de Caso de Uso do Sistema

Após esta fase ficou estabelecido que o sistema teria duas interfaces, uma voltada para o profissional, com toda a parte relativa a cadastramentos de alunos, atividades, elementos, etc, além da programação da sequencia de atividades de cada criança. E a interface disponibilizada para a criança, que por ser tratar de um sistema 
voltado para alfabetização é referenciado como aluno, ficando reservado a este o papel meramente de visualizador e executor das atividades montadas pelo profissional.

Todo este processo teve a supervisão de profissionais que lidam diariamente com a construção das atividades alfabetizatórias, que atualmente são elaboradas de forma manual demandando tempo e habilidades compatíveis. Uma vez elaborados os modelos de tela que serão apresentados a seguir, de forma resumida, se fez necessário definir o nível de acesso de cada usuário do sistema, provendo assim feedback ao mesmo das ações a serem permitidas aos usuários. Ficou estabelecido que esta configuração seria realizada por módulo implementado, concedendo ao profissional permissão para as ações de visualização, edição, bloqueio e execução. A criança ficaria limitada apenas às ações de visualização e execução dentro do módulo de atividades. A Figura 2 mostra em detalhes como seria realizada esta configuração.

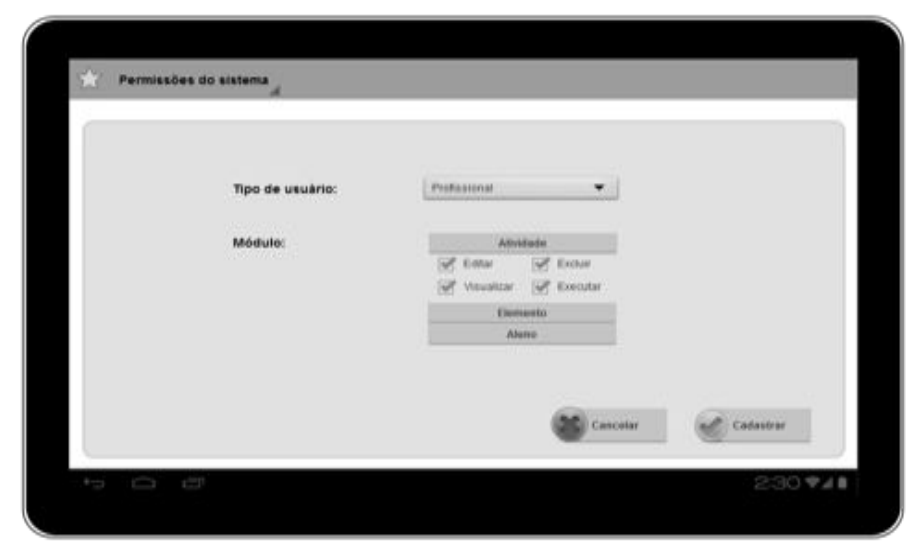

Figura 2 - Configuração de Nível de Acesso

A divisão do sistema em módulos foi necessária devido à complexidade envolvida com a criação da ferramenta. A fim de permitir um melhor controle aos desenvolvedores, uma vez que se pretende não apenas propiciar a criação de atividades por parte do profissional, mas também fazer deste um verdadeiro sistema de informação, onde será possível acompanhar a evolução da criança, através da geração de relatórios, gráficos comparativos, definição de metas a serem cumpridas, além da definição de recompensas, dicas para crianças no ato de execução das atividades, passagem automática de nível da criança etc.

Uma parte fundamental no sistema é a elaboração de atividades, porem não é possível realizar esta tarefa sem que antes existam elementos para compor as mesmas, então se pensou em criar um módulo totalmente voltado para esta finalidade. Em pesquisas que antecederam a modelagem deste módulo buscou-se imagens que melhor representassem a dinâmica alfabetizatória, estas formaram a biblioteca de elementos do sistema ilustrada na Figura 3. Ficou estabelecido que as imagens, para uma melhor organização, seriam divididas em categorias e subcategorias, o que de certa forma beneficiaria qualquer mecanismo de busca que viesse a ser implementado. Definiu-se também que cada elemento teria quatro variantes, sendo estas nomeadas como foto, figura, desenho e sombra, provendo maiores possibilidades de variação das atividades ao profissional responsável pela sua elaboração. Lembrando que todas estas escolhas procuram seguir o padrão atualmente realizado na instituição pesquisada, totalmente alinhada à metodologia TEACCH. 


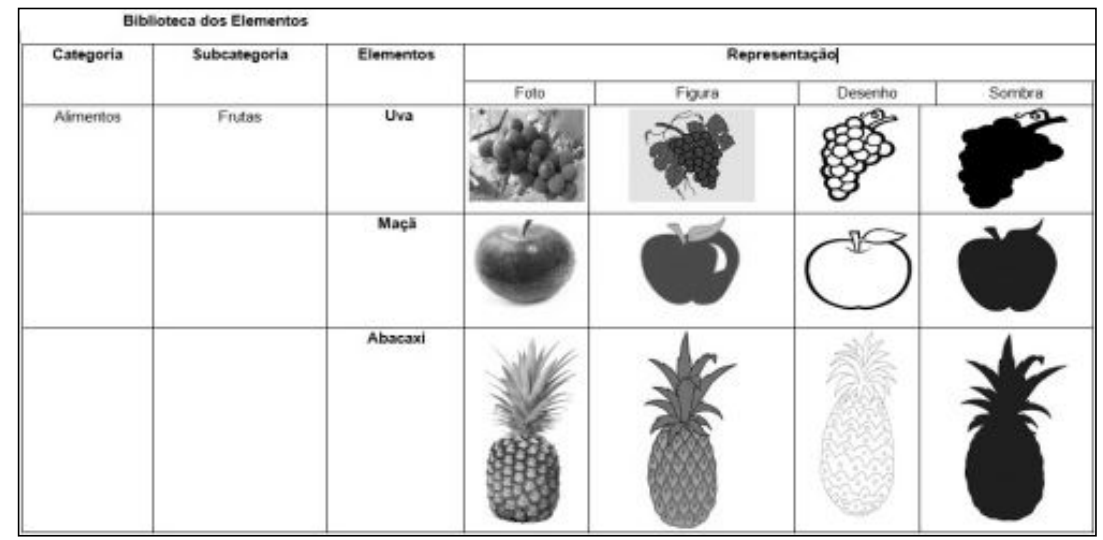

Figura 3 - Trecho da Biblioteca de Elementos do Sistema

Antes a qualquer tentativa de implementação foi necessário organizar todas as relações existentes entre os módulos inicialmente pensados para o sistema, pois o entendimento destas associações propiciaria a criação de uma ferramenta mais confiável e consequentemente de maior qualidade. Partiu-se então para a modelagem do banco de dados do sistema, apresentado na Figura 4. Esta prática foi necessária visto que, evita, futuramente, a modificação de módulos já implementados para adequação de novas funcionalidades que surgissem no processo de desenvolvimento do sistema, otimizandoo e facilitando a manutenção do sistema como um todo. A elaboração deste modelo evidenciou as classes iniciais pretendidas para o sistema, após a análise dos requisitos. Estas serviram de suporte para entender quais as funcionalidades críticas, ou seja, aquelas que mereciam uma maior atenção por parte dos desenvolvedores. Além disso, foi possível também idealizar os métodos, que irão efetivamente executar as ações em nível de sistema, responsáveis por tais funcionalidades.

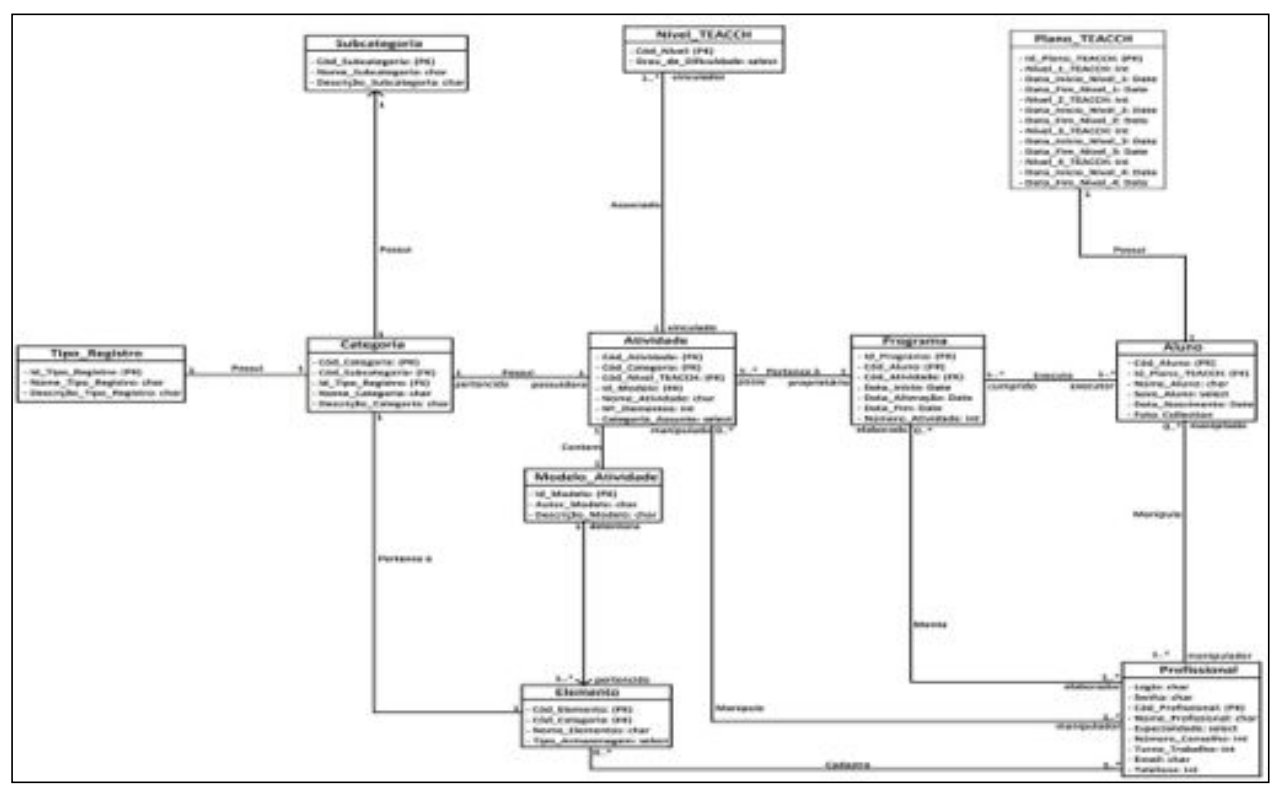

Figura 4 - Modelo de Banco de Dados do Sistema

Uma vez definidos os elementos, o próximo passo é cadastrá-los no sistema. No entanto, faz-se necessário pensar nos atributos que um elemento deve conter para ser 
inserido no sistema. Além da categoria e subcategoria, pensou-se em identificadores para cada elemento como código (Id) e nome, sendo estes essenciais, pois em etapas posteriores serão utilizados para definir as respostas nas atividades. Também foi definido que haverá duas possibilidades de inserção do elemento no sistema; manual e via arquivo. A forma manual permitirá ao profissional digitar alguma palavra ou letra e esta ser disponibilizada no sistema como elemento a ser utilizado na construção de uma atividade, é claro que antes de qualquer visualização por parte da criança este elemento passaria por um processo de edição deixando o mesmo com fontes apropriadas para manipulação do aluno. A outra forma possível de inserção será através de upload de arquivos de imagens no sistema, que possibilitará ao profissional cadastrar as quatro variantes de uma determinada imagem como sendo apenas um elemento, sendo este separado para o caso do profissional desejar fazer uso de apenas uma dessas variantes para compor uma atividade. A Figura 5 apresenta em detalhes este processo.

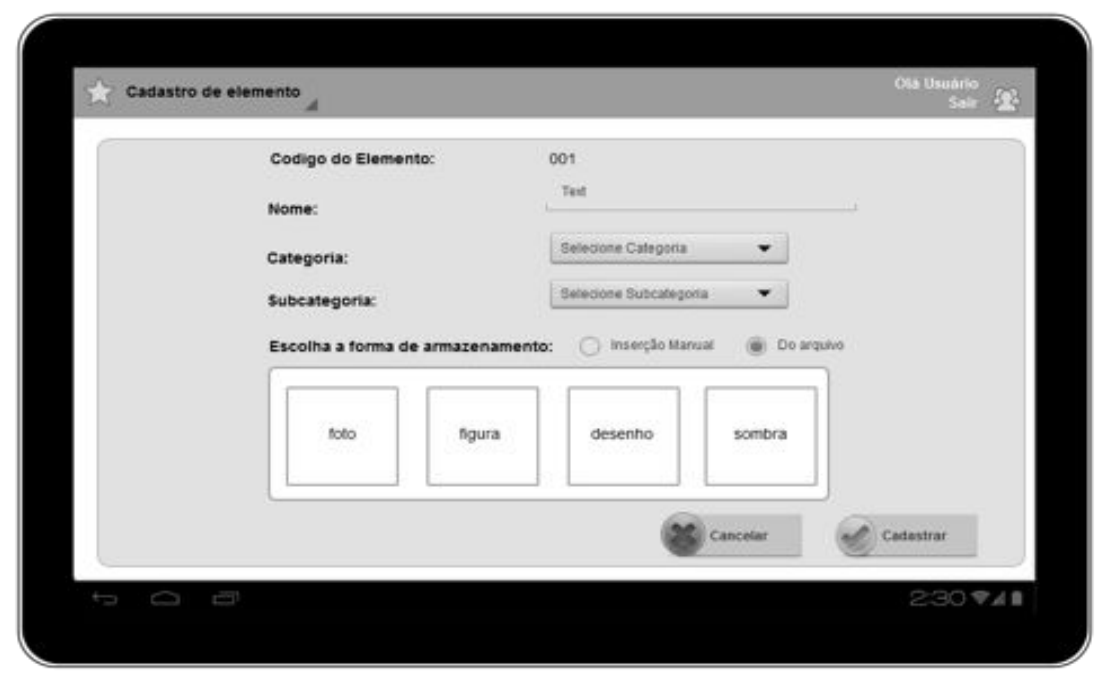

Figura 5 - Tela Cadastro de Elemento: Opção Do arquivo

Cabe ressaltar que o processo de cadastramento da biblioteca de elementos é dinâmico, ou seja, não é necessário que este esteja concluído para que o profissional esteja apto a elaborar uma atividade, basta que existam elementos suficientes para povoar a mesma.

Outro foco de atenção está na interface de Cadastro de Atividades, apresentada na Figura 6. A AMA-AL atualmente trabalha com três formas de atividades: pareamento, classificação e sequenciamento, cada uma focando em carências específicas na criança. Pretende-se reproduzir esse processo, possibilitando ao profissional interagir com a ferramenta a fim de montar novas atividades e disponibilizá-las no acervo, e não apenas utilizar as já cadastradas. A construção de uma atividade especifica deverá obedecer a uma série de etapas onde inicialmente o profissional deverá informar atributos referentes à atividade a ser cadastrada, logo em seguida escolherá um modelo de atividade desejado, sendo este uma espécie de mapa contendo possíveis posições dos elementos na atividade, e por fim escolherá os elementos que povoarão a atividade.

Nesta última etapa, o sistema se encarregará de disponibilizar os elementos até então cadastrados no sistema, que estarão sujeitos a filtros, com o intuito de reduzir o 
escopo de busca. Outro recurso oferecido pela interface será a possibilidade de busca por um elemento específico no sistema, bastando para isso o profissional informar no campo termo de busca uma palavra ou trecho de palavra que represente o elemento cadastrado. Flexibilidade e dinamismo estarão presentes neste processo, pois o sistema fornecerá possibilidades de escolha ao profissional, que terá à sua disposição os mecanismos de busca anteriormente apresentados facilitando a procura pelo elemento que melhor represente o proposito da tarefa, com o intuito de otimizar o trabalho do profissional.

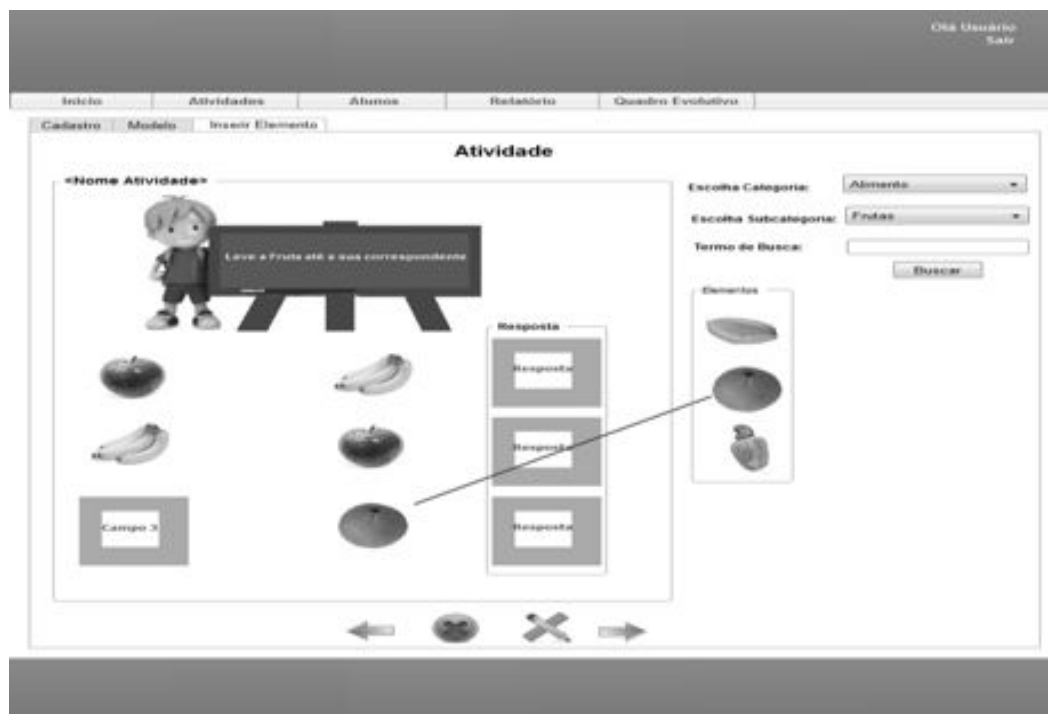

Figura 6 - Tela Cadastro de Atividades

Outro modelo importante que merece ser ressaltado refere-se à interface de elaboração do programa da criança, apresentada na Figura 7, que propiciará a montagem de uma sequencia de atividades a ser executada em determinado período pela criança. A programação será realizada por criança cadastrada, podendo ser do tipo diária, semanal ou mensal.

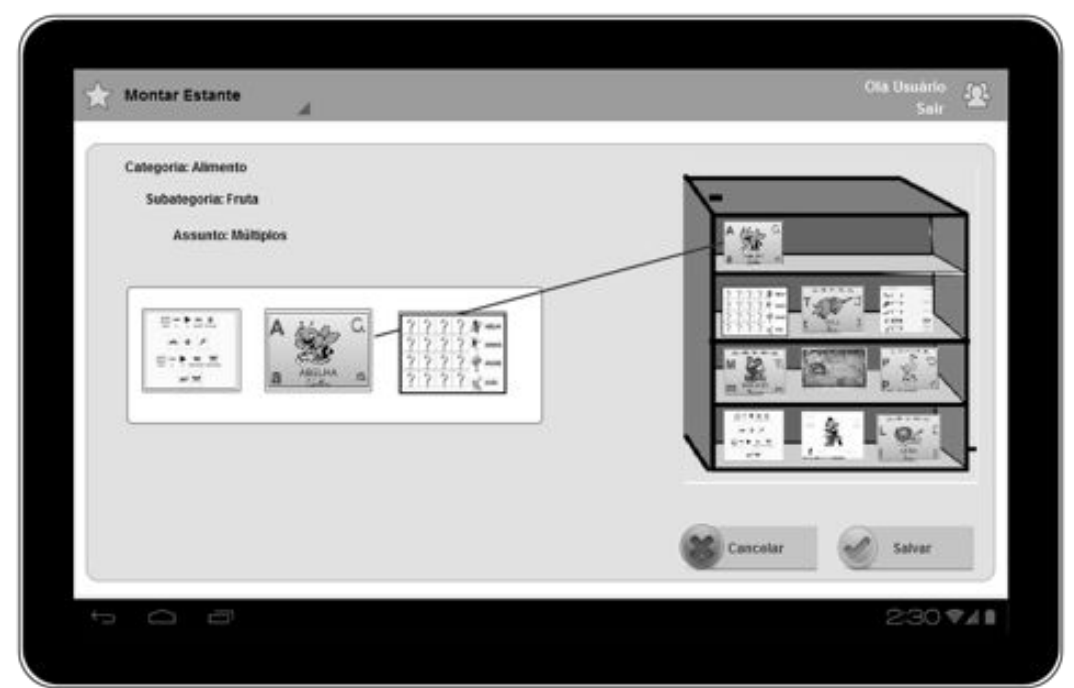

Figura 7 - Tela de Montagem da Programação da Criança 
Mecanismos para filtragem das atividades a serem apresentadas para escolha também serão disponibilizados pela interface, e estes terão como parâmetro a categoria, subcategoria e nível TEACCH de atividade desejado. Uma vez montado um programa o mesmo só poderá ser excluído caso não tenha sido iniciado por uma criança, o que poderia gerar inconsistências no quadro evolutivo da criança. Os programas também terão data limite para execução estabelecendo metas a serem alcançadas pela equipe envolvida com o tratamento de determinada criança.

\section{Conclusão}

A ferramenta de software, cuja especificação está descrita neste artigo, encontra-se em fase de desenvolvimento dos módulos iniciais. Acredita-se que a criação desta ferramenta, propiciará a otimização no tratamento de crianças autistas especialmente no que concerne a alfabetização. Esta potencialização reflete-se na automatização do processo de construção das atividades, por parte do profissional, possibilitando uma maior adequação das tarefas ao nível de desenvolvimento da cada criança, uma vez que a flexibilidade dada ao processo permitiria trabalhar carências especificas da criança através de imagens e estímulos voltados para diminuir gradualmente os déficits apresentados. Além disso, a ferramenta possibilitará ao profissional, após uma prévia investigação da rotina da criança, utilizar imagens que representem personagens de maior afinidade da criança, o que ajudará a manter a criança atenta a proposta alfabetizatória que está sendo apresentada.

Por outro lado, a própria manipulação de uma ferramenta multimídia ajudará o profissional a controlar a atenção da criança ao tratamento que está sendo aplicado, pois todo o uso de cores, animações, elementos, etc, tem sido cuidadosamente pensado procurando obedecer a critérios rigorosos de seleção estabelecidos pela metodologia TEACCH, utilizada como base para a construção da ferramenta. Até a forma como cada atividade deverá ser executada também se constitui uma característica que merece destaque, pois a própria dinâmica colocada no processo exige que a criança manipule os elementos dentro da atividade, possibilitando que novos movimentos sejam trabalhados, fazendo com que a mesma abandone gradualmente os movimentos estereotipados característicos do espectro autista. A pretensão é desenvolver esta ferramenta para múltiplas plataformas, maximizando ainda mais os benefícios com a elaboração da mesma, sendo esta inicialmente voltada para tablet, podendo ser adaptada para desktop ou até mesmo para uma versão web, propiciando um tratamento de forma integral a estas crianças, uma vez que o mesmo poderá ser realizado dentro da própria residência da criança, em qualquer horário.

Esforços estão sendo envidados no intuito de concluir a fase de implementação dos módulos iniciais, bem como na elaboração de novos módulos essenciais ao tratamento oferecido, como o de cadastramento de recompensas e dicas a serem fornecidas à criança no ato de execução das atividades, que são fundamentais uma vez que provêem estímulos e ajuda as crianças que apresentam os déficits de forma mais acentuada. Este módulo estará associado ao de atividades e será disponibilizado na forma de etapas no ato de cadastramento das mesmas. Além disso, módulos referentes ao acompanhamento evolutivo da criança estão atualmente sendo discutidos e especificados, com o intuito de gerar estatísticas e indicadores, que facilitarão o trabalho dos profissionais, seja na definição da passagem de nível TEACCH da criança, ou na 
contabilização do número de acerto, erros, tempo de resposta de uma atividade ou até mesmo de uma sequência de atividades. A intenção é automatizar todo este processo.

Apesar de já existirem softwares utilizados na alfabetização de crianças autista, estudos indicam que os melhores resultados são alcançados por meio da adaptabilidade deste processo à realidade de cada criança, uma vez que estas apresentam as características do espectro de forma subjetiva. A criação de uma ferramenta totalmente alinhada aos parâmetros adotados pela metodologia TEACCH será fundamental neste aspecto propiciando a gradual autonomia destas crianças para enfrentamento de um mundo cada vez mais competitivo e hostil. Tão logo os módulos iniciais da ferramenta proposta estejam implementados, os mesmos serão apresentados às crianças atendidas na AMA-AL para manipulação e averiguação de eventuais ajustes.

\section{Referências}

Ajuriahuerra, J. (1977) Las Psicosis Infantiles. In: Manual de Psiquiatría Infantil. 4 ed. pp. 673-731.Barcelona: Toray-Masson; 1977.

Bernardi, S. T. (2010) Utilização de Softwares Educacionais nos Processos de Alfabetização, de Ensino e Aprendizagem com uma Visão Psicopedagógica, v. 5, n. 10. Revista de Educação do IDEAU, Instituto de Desenvolvimento Educacional do Alto Uruguai - IDEAU. Getúlio Vargas - RS.

Camargos Jr., W. (coord.). (2005) Transtornos Invasivos do desenvolvimento: $3^{\circ}$ Milênio. 2 ed. Brasília, DF: Presidência da República, Secretaria Especial dos Direitos Humanos, CORDE.

Coelho, M; Espírito Santo, A. (2006) Necessidades Educativas Especiais de Carácter Permanente/ Prolongado no Contexto da Escola Inclusiva. CENFOCAL (Centro de Formação Contínua de Professores de Ourique), Castro Verde.

De Leon, V. C. (2002) Estudo das Propriedades Psicométricas do Perfil Psicoeducacional PEP-R: Elaboração da Versão Brasileira. Dissertação de Mestrado em Psicologia, Universidade Federal do Rio Grande do Sul - Instituto de Psicologia. Porto Alegre - RS.

Kwee, C. S.; Sampaio, T. M. M. (2006) Abordagem Transdisciplinar no Autismo: O Programa TEACCH. Dissertação de Mestrado Profissionalizante em Fonoaudiologia. Universidade Veiga de Almeida. Rio de Janeiro - RJ.

Mello, A. M. S. Ros de. (2001) Autismo: Guia Prático. 2 ed. Brasília, CORDE.

Morais, G. A. S. Alfabetizar Letrando: Desafios da Prática Pedagógica Alfabetizadora. 2010. Universidade Federal do Piaú, Teresina - PI.

Rapin, I. (1991) Autistic children: diagnosis and clinical features. Pediatrics, 87, pp. 751-60.

Rutter, M; Schopler, E. (1992) Classification of pervasive developmental disorders: some concepts and practical considerations. Journal Autism Development Disorders, 22, pp. 459-82.

SANTOS, R. P. R. (2009) A Linguagem em Crianças com Perturbações do Espectro do Autismo: Análise Morfossintáctica. Dissertação de Mestrado, Universidade de Aveiro. 